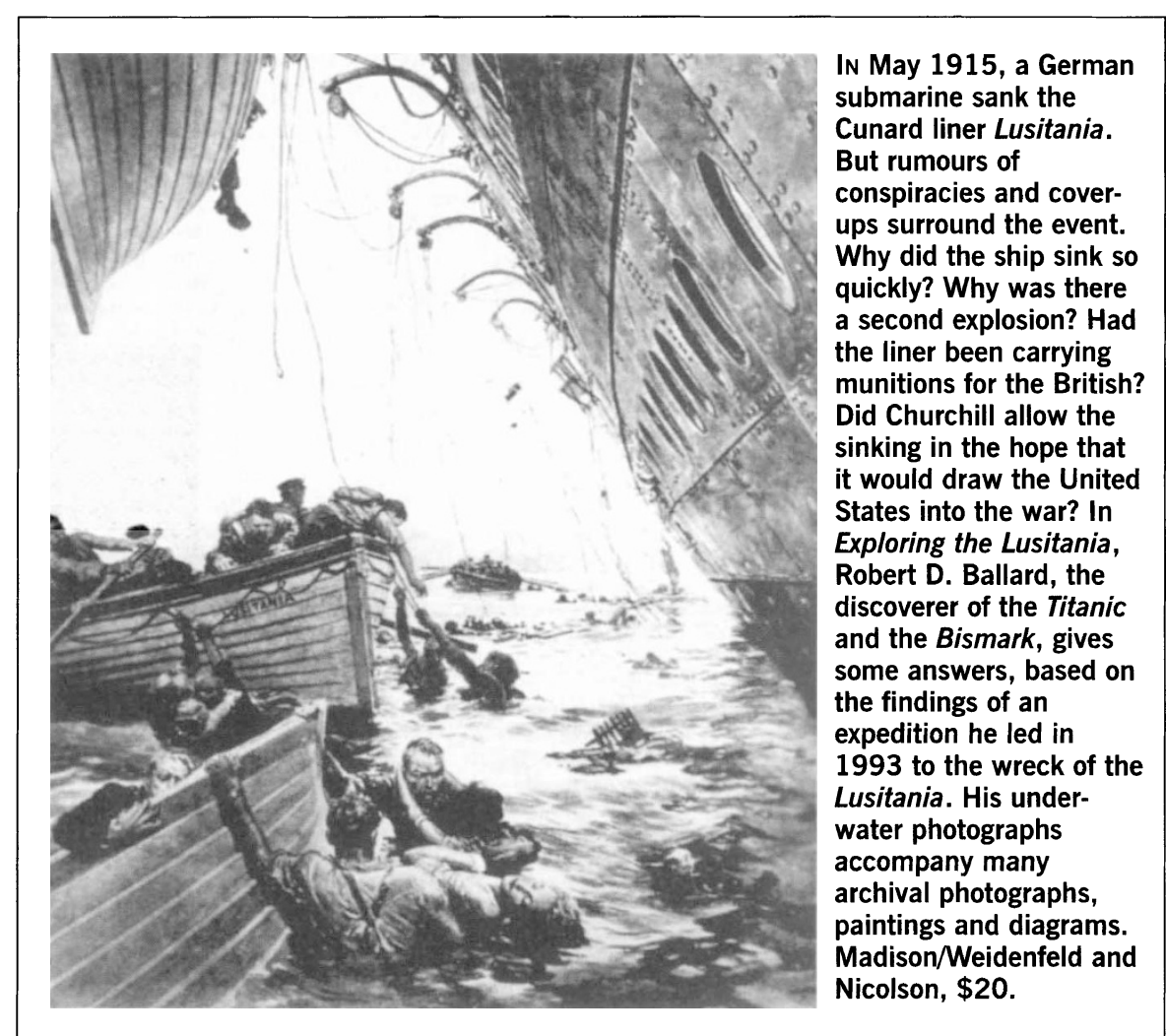

asts of IQ, comes in for effective treatment. The book also deals quite competently with the folk ideas of racial superiority in sports. Its centrepiece involves the antiquated local anthropology validating the subjugation of Eastern European Gypsies, a tragic and sobering read.

The book is therefore principally about current events rather than being a weighty scientific discussion of underlying issues. Nevertheless, for all its shortcomings as a scholarly analysis, this is a useful book, not to be tossed away. It strives to be on the side of the angels, and on the side of science (although I am not entirely convinced the author fully understands the basis for this). In style it is often glib without plummeting into condescension. The author appreciates the gravity of the topic he has chosen and clearly wishes his book to do some good in the world. That is admirable, and I hope and expect that his wish will be fulfilled.

Ultimately, though, he is in over his head. There really are some thoughtless, disingenuous or downright evil scientists out there, establishing their reputations on the backs of the downtrodden and voiceless. That is bad all around - bad for society and bad for science. Effectively debunking them requires a hierarchical vision, involving not only scientific critiques of methodology and inference but also meta-scientific critiques of just what science can and cannot say about certain things, the role of science as validation (and the attendant responsibilities of scientists) and the very nature of scholarship and academic professionalism. Otherwise we are left simply with people who do think there are basic divisions of the human species with unequal worth, and people who don't - in other words, a legitimate-seeming scientific impasse, which ultimately works to the detriment of both science and social progress. The only bona fide student of human biological variation we meet in this book is Fatimah Jackson, who is curiously represented as an Afrocentric antithesis of Rushton - in this way simultaneously discrediting the mainstream Jackson and legitimizing the atavistic Rushton.

With a firmer grounding in the relevant scientific literature, The Race Gallery could have broken down the problem of racial science into an answerable series of smaller questions.

First, is the human species divisible into a small number of natural groups? No. This was known to Buffon and Blumenbach and summarized epigrammatically by Frank Livingstone in 1962 (as quoted by Kohn): "There are no races; there are only clines".

Second, is it legitimate to compare populations derived from diverse regions? Yes. Primary research in journals such as American Journal of Physical Anthropology, Human Biology, Annals of Human Biology and American Journal of Human Biology has been doing this for decades. (This literature is not cited by Kohn.)

Third, if they are found to differ, is the difference biologically based? Maybe. Different facial features of a Swede and a Yoruba may be biologically based, but the different languages they speak are surely not. A century of acculturation studies shows that people's minds and bodies can change radically within a generation after migration. A consistent observation of difference is therefore not a reliable indicator of a biological basis for that difference. A specific observed difference may be constitutionally rooted, but requires a higher standard of validation than just consistency of observation to establish it.

Finally, do populations have different intellectual abilities? Probably not. The reason is simply that ability is a folk concept and not amenable to scientific analysis. Because a test is a performance, and ability is only one component of a performance, it follows that performance is not a reliable estimator of ability. A good performance is a demonstration of ability; a bad performance may not at all be a demonstration of the lack of ability. So the fundamental falsehood is the claim that we can say anything scientific at all about individual ability or potential - much less those of groups. History does tell us, however, that populations derided for their abilities in one era are often quite competent in another.

Without a scientific approach to human potential, we are left with two poles of social action: we can try to identify and cultivate diverse talents as widely as possible (by investing our resources in education, day care and children's enrichment programmes); or we can condemn large groups of people on the basis of their lack of performance, denying both the right of the subjects to be judged as individuals and the possibility of society benefiting from the talents with which they are endowed. Neither alternative is particularly scientific; but the first is at least humanitarian.

Jonathan Marks is in the Department of Anthropology, Yale University, PO Box 208277, New Haven, Connecticut 06520 8277, USA.

\section{Children's Books}

Next week's issue contains Nature's Children's Books supplement, in which reviewers - young and old alike - will look at some of the science books and software for children recently published in the United Kingdom and the United States. Subjects include dinosaurs, natural history, computers, fire, energy, the weather, genetics and drugs. And Frances Balkwill, author of several awardwinning children's books, inluding Cells Are Us and The Egg and Sperm Race, offers her thoughts on the business of writing successful books for youngsters. 